\title{
A Sensitizing Regimen of Amphetamine Impairs Visual Attention in the 5-Choice Serial Reaction Time Test: Reversal by a DI Receptor Agonist Injected into the Medial Prefrontal Cortex
}

\author{
Paul J Fletcher*, 1,3,4, Catherine C Tenn ${ }^{2,5}$, Judy Sinyard', Zoë Rizos' and Shitij Kapur ${ }^{2,3}$ \\ 'Section of Biopsychology, Centre for Addiction and Mental Health, Toronto, ON, Canada; ${ }^{2}$ SchizophrenialPET Centre, Centre for Addiction and \\ Mental Health, Toronto, ON, Canada; ${ }^{3}$ Department of Psychiatry, University of Toronto, Toronto, ON, Canada; ${ }^{4}$ Department of Psychology, \\ University of Toronto, Toronto, ON, Canada
}

\begin{abstract}
Exposure to repeated, intermittent, escalating doses of amphetamine in rats disrupts information processing in several tasks. Some of these deficits, notably impaired attentional set shifting, may reflect altered prefrontal cortex function. This study examined the effects of repeated treatment with amphetamine on performance in the 5-choice serial reaction time test. This test measures sustained visual attention, a behavior that is known to require the prefrontal cortex. Rats were trained to respond to a brief light stimulus presented randomly in one of five spatial locations, with 100 trials per session. Once performance had stabilized rats were treated with escalating doses of amphetamine (three injections per week for 5 weeks at I-5 mg/kg per week); testing was continued on nondrug days, and for several weeks of withdrawal. During the amphetamine-treatment and withdrawal phases accuracy of responding was unaffected, but errors of omission increased. Lengthening the stimulus duration abolished this effect. Reducing the stimulus duration also reduced response accuracy and this effect was more marked in amphetamine-treated rats. Both reduced accuracy, and increased omissions, seen in amphetamine-treated rats were reversed by injecting the DI receptor agonist SKF38393 into the medial prefrontal cortex. This treatment also prevented the decline in accuracy in control animals that resulted from reducing the stimulus duration. These results, indicating that exposure to amphetamine induces a long-lasting deficit in visual attention, add to a growing list of deficits suggesting that amphetamine-sensitized state may model the cognitive deficit state in schizophrenia. The reversal of these deficits by a DI receptor agonist provides further evidence that prefrontal DI dopamine receptors are involved in cognition, and may be a potential target for treatment of impaired cognition in schizophrenia.

Neuropsychopharmacology (2007) 32, II22- I 132. doi:I0.1038/sj.npp. I30 I22I; published online I 8 October 2006
\end{abstract}

Keywords: amphetamine; visual attention; dopamine DI receptor; prefrontal cortex; schizophrenia

\section{INTRODUCTION}

Repeated, intermittent treatment with psychomotor stimulants such as amphetamine can enhance the subsequent behavioral and neurochemical effects of the drug (Robinson and Becker, 1986; Vanderschuren and Kalivas, 2000). Such sensitization reflects long-term, drug-induced, neuroadaptive changes. The most frequently studied changes are those

*Correspondence: Dr PJ Fletcher, Section of Biopsychology, Centre for Addiction and Mental Health, 250 College Street, Toronto, ON, Canada M5T IR8, Tel: + | 4165358501 X4058, Fax: + | 416979 6942, E-mail: Paul_Fletcher@camh.net

${ }^{5}$ Current address: DRDC Suffield PO Box 4000, Station Main, Medicine Hat, Alberta, Canada TIA 8K6.

Received 9 June 2006; revised 25 July 2006; accepted 25 August 2006 Online publication: 8 September 2006 at http://www.acnp.org/ citations/Npp090806060391/default.pdf related to the functioning of mesostriatal and/or mesolimbic dopamine (DA) systems. These changes are the ones that underlie the sensitized locomotor responses, and augmented efflux of DA in striatal regions, elicited by challenge doses of amphetamine (Paulson and Robinson, 1995; Robinson et al, 1988).

In humans, chronic amphetamine use can lead to psychosis (Sato et al, 1992); as well, acute challenge with amphetamine can induce psychosis in individuals with schizophrenia at doses that are ineffective in controls (Lieberman et al, 1987). Individuals with schizophrenia may show enhanced release of DA, compared to control subjects, following amphetamine (Abi-Dargham et al, 1998; Laruelle et al, 1999). These apparent increased psychotomimetic and neurochemical effects of amphetamine in schizophrenia resemble the sensitized responses observed in animal subjects. Indeed, it has been suggested that a 
sensitization-like process may contribute to the pathophysiology of schizophrenia (Howes et al, 2004; Laruelle, 2000; Lieberman et al, 1997; Ujike, 2002). Accordingly, the amphetamine-sensitized state has attracted interest as a model for aspects of schizophrenia, especially those related to psychosis.

In recent years, attention has been directed towards understanding, and treating the cognitive deficit state in schizophrenia. The amphetamine-induced sensitized state may be relevant to this aspect of schizophrenia given the increasing number of reports describing information processing deficits in rats previously exposed to amphetamine. These deficits include disruptions of latent inhibition (Murphy et al, 2001; Russig et al, 2002, 2003; Tenn et al, 2005), and of prepulse inhibition (PPI) of the acoustic startle reflex (Tenn et al, 2003, 2005). Latent inhibition (Ellenbroek et al, 1997; Jeanblanc et al, 2002; Joseph et al, 2000; Solomon and Staton, 1982) and PPI (Kodsi and Swerdlow, 1994; Swerdlow et al, 1990; Wan and Swerdlow, 1996) are disrupted by lesions of, or local neurochemical manipulations within, the nucleus accumbens and/or dorsal striatum. Therefore, the effects of the amphetamine-induced sensitized state on latent inhibition and PPI may be consistent with the notion that this state induces functional changes in dopaminergic pathways.

A number of cognitive deficits have been described following exposure to repeated amphetamine treatment. In non-human primates a sensitizing regimen of amphetamine disrupts working memory (Castner et al, 2005) whereas in rats attentional set-shifting ability is impaired after amphetamine exposure (Fletcher et al, 2005). Working memory (Goldman-Rakic, 1995; Jones, 2002; Pratt and Mizumori, 2001) and attentional set-shifting (Birrell and Brown, 2000; McAlonan and Brown, 2003) involve the medial prefrontal cortex (mPFC), and so the deficits in these cognitive abilities in the amphetamine-sensitized state might result from altered PFC function. Reversal learning is impaired following amphetamine or cocaine exposure, and this likely reflects altered orbitofrontal cortex function (Jentsch et al, 2002; Schoenbaum et al, 2004).

Rats with a history of amphetamine treatment appear also to have attentional deficits. In one study, rats that previously self-administered amphetamine showed reduced accuracy and had increased errors of omission in the 5choice serial reaction time task (Dalley et al, 2005); these deficits are similar to those observed after damage to selected regions of the PFC (Chudasama et al, 2003; Muir et al, 1996; Passetti et al, 2002). Again, this provides some suggestive evidence that repeated exposure to amphetamine alters PFC function. However, one feature of the results reported by Dalley et al (2005) is that the effects observed in rats that self-administered amphetamine were relatively transient, lasting only for a few days. This contrasts with other data showing that behavioral deficits, such as impaired set-shifting, disrupted LI, and attenuated PPI, resulting from previous amphetamine exposure persist for at least several weeks after amphetamine treatment has stopped (Fletcher et al, 2005; Tenn et al, 2005). Discrete, intermittent injections of stimulants are generally more likely to induce sensitization than more frequent or sustained exposure to the drugs (Ben-Shahar et al, 2004; Nelson and Ellison, 1978; Post, 1980; Robinson, 1984;
Robinson and Becker, 1986). For example, daily $1 \mathrm{~h}$ cocaine self-administration sessions induce a sensitized state whereas daily $6 \mathrm{~h}$ self-administration sessions do not (Ben-Shahar et al, 2004). Thus, the regimen of stimulant exposure plays a role in determining the types of long-term changes that accrue from drug exposure.

In our work, we have used a schedule of drug injections involving intermittent ( 3 days per week) treatment with a slowly escalating increase in dosage (Fletcher et al, 2005; Tenn et al, 2003, 2005). Therefore, the first objective of the present experiments was to examine the influence of this regimen of amphetamine treatment on visual attention using the 5-choice serial reaction time test. Having found an attentional deficit in amphetamine exposed rats a second objective was to determine the effects of injecting the D1 dopamine receptor agonist SKF38393 into the PFC on this deficit. The rationale for this part of the work is (1) the general suggestion that the D1 receptor in the PFC plays a role in cognition (Goldman-Rakic et al, 2004), (2) the finding that D1 receptor activation in the medial PFC improves attentional performance in poorly performing rats (Granon et al, 2000), and (3) the finding that deficits in attentional set-shifting arising from amphetamine exposure are reversed by SKF38393 injected into the mPFC (Fletcher et al, 2005).

\section{MATERIALS AND METHODS}

\section{Subjects}

Male Sprague-Dawley rats (Charles River, QC) were used. They were individually housed in hanging clear plastic cages on a $12 \mathrm{~h}$ light-dark cycle (lights on at 0800) in a temperature controlled room $\left(22^{\circ} \mathrm{C}\right)$. During training and testing, food was restricted to $18-20 \mathrm{~g}$ per day. Water was available ad-libitum in the home cages. All training and testing occurred during the light cycle.

\section{Sensitization Regimen}

Rats were assigned to two groups and received an i.p. injection of D-amphetamine sulfate (Sigma-RBI, Oakville, $\mathrm{ON}$ ), or $0.9 \%$ saline (Sal; $1 \mathrm{ml} / \mathrm{kg}$ ) 3 days per week for 5 weeks. One injection per day was administered on Monday, Wednesday, and Friday. The amphetamine dose increased from 1 to $5 \mathrm{mg} / \mathrm{kg}$ at a rate of $1 \mathrm{mg} / \mathrm{kg}$ each week.

\section{Apparatus}

Training and testing for the 5-choice serial reaction time test were conducted in four operant boxes (Med Associates, St Albans, VT) measuring $33 \times 31 \times 29 \mathrm{~cm}^{3}$. The rear stainless-steel wall of the chamber was curved and contained an array of $52.5 \mathrm{~cm}$ square apertures located $2.5 \mathrm{~cm}$ above the floor and $2.5 \mathrm{~cm}$ apart. An infrared photodetector was located at the entrance to each aperture $1 \mathrm{~cm}$ from the front. A 3-W yellow stimulus light, $6.4 \mathrm{~mm}$ in diameter, was centered at the back of each aperture. The front wall of the chamber was constructed of stainless-steel. A $5 \mathrm{~cm}$ square reinforcer magazine was centered in this wall $2.5 \mathrm{~cm}$ above the floor. The magazine contained an infrared photodetector at the entrance, and a light mounted in the 
roof. A motor driven dipper arm could be raised to deliver $0.06 \mathrm{ml}$ liquid through a hole in the floor of the magazine. Each operant box was illuminated by a houselight, and was enclosed in a sound-attenuating chamber equipped with a ventilation fan. The boxes were controlled by an IBMcompatible computer running Med-PC for Windows.

Locomotor activity testing was conducted in standard clear Plexiglas housing cages $(27 \times 48 \times 20 \mathrm{~cm})$. A row of six infrared photocell emitters and detectors was positioned along the long axis of the cage $3 \mathrm{~cm}$ above the floor. A computer was used to detect and record the number of photobeam interruptions.

\section{Training}

For 2 days before training rats were provided with free access to a bottle containing $10 \%$ sucrose to allow them to become familiar with this solution. For the first three $30 \mathrm{~min}$ training sessions, rats were placed in the operant boxes with the magazine light illuminated and the dipper raised according to a random time $30 \mathrm{~s}$ schedule. Each dipper elevation presented $0.06 \mathrm{ml} 10 \%$ sucrose for $2.5 \mathrm{~s}$. Subsequently the animals were placed in the chamber with one of the five response apertures illuminated. A response in that aperture extinguished that light, illuminated the magazine light and resulted in dipper elevation until the reward had been collected. Sessions lasted until 60 trials had been completed, or for $30 \mathrm{~min}$. When each animal had successfully acquired this task (approximately 5 days) training on the 5-choice serial reaction time task proper began. This task requires the rat to discriminate brief visual stimuli presented randomly to one of the five spatial locations (Robbins, 2002).

The start of the session began with illumination of the houselight and the magazine light, and elevation of the dipper for $2.5 \mathrm{~s}$. A nose poke in the magazine began the first trial. After a fixed inter-trial interval (ITI) one of the five light stimuli was illuminated for a brief period; a response in that hole while the light was on, or during a short limited hold period, resulted in elevation of the dipper for $2.5 \mathrm{~s}$, and illumination of the magazine light. A nose-poke into the magazine to collect the reinforcer initiated the ITI to the next trial. Incorrect responses in any of the other four holes were not reinforced but were followed by a $5 \mathrm{~s}$ time out period of darkness; failures to respond within the limited hold period (omissions) were also followed by a $5 \mathrm{~s}$ time out. A time out period also followed perseverative responding, defined as additional responses made in any of the five holes before reinforcer collection. At the end of the time out periods, the magazine light was turned on and a nose-poke in the magazine began the next trial. Responses during the ITI were recorded as premature responses, and were followed by a time out. Magazine responses at the end of these time out periods restarted the same trial. Sessions lasted for $30 \mathrm{~min}$, or until rats had completed 100 trials; each stimulus was presented 20 times in a random order.

Training began with a stimulus duration of $30 \mathrm{~s}$ and a limited hold of $30 \mathrm{~s}$. These parameters were altered dependent upon performance until the final parameters were reached. These parameters were $1 \mathrm{~s}$ stimulus duration, $5 \mathrm{~s}$ limited hold. The length of the time out was always $5 \mathrm{~s}$; the ITI was also held constant at $5 \mathrm{~s}$ except in those experiments where ITI manipulation was the experimental variable. Training took approximately 50 days until rats were consistently responding with an accuracy of $>85 \%$ and $<15 \%$ omissions. Rats were then divided into two matched groups (saline $v s$ amphetamine) based on baseline preoperative performance. A number of dependent variables were recorded. Accuracy of responding was measured by determining the percent correct responses (correct responses $/$ (correct + incorrect responses $) \times 100$ ) and the percent omissions (number of omissions/total number of trials $\times 100)$. Speed of responding was determined by measuring the latency to respond correctly, as well as the latency to collect the reinforcer once a response had been made. The number of premature, perseverative, and time out responses were recorded.

\section{Surgery and Histology}

Rats were anaesthetized with sodium pentobarbital $(60 \mathrm{mg} /$ $\mathrm{kg}$ ) and underwent surgery to implant $23-\mathrm{G}$ guide cannulae (11 mm in length) bilaterally into the prefrontal cortex. The stereotaxic coordinates (Paxinos and Watson, 1998) were: AP: $+3.2 \mathrm{~mm}$ from bregma, $\mathrm{L}:+0.7 \mathrm{~mm}$ from midline and DV: $-3.0 \mathrm{~mm}$ from the skull. Obdurators $(11 \mathrm{~mm})$ were used to keep the guide cannulae patent. At the completion of the experiments rats were deeply anaesthetized with Somnotol and a volume of $0.5 \mu \mathrm{l}$ fast-green dye was injected into each brain site to aid in the localization of the injection sites. The brains were removed and stored in formaldehyde for at least 7 days, and then stored in 30\% sucrose solution. Brains were then frozen, cut in a cryostat in $40 \mu \mathrm{m}$ sections and stained with cresyl violet.

\section{Experiments}

Experiment 1: effects of amphetamine sensitization and withdrawal. Rats were trained on the task for 6 or 7 days per week until all rats were responding with an accuracy of $85 \%$ correct responses, with fewer than $15 \%$ omissions. The rats were then divided into two groups based on baseline performance over the preceding 7 days. Nine rats were assigned to receive amphetamine injections and seven rats received saline injections. Throughout the course of the sensitization regimen rats received their injections on Mondays, Wednesdays and Fridays. They were not run on the task on these days. However, rats were tested on the task on Tuesdays, Thursdays, and Saturdays. This protocol was followed for the 5 weeks of the sensitization regimen, and for 5 weeks after cessation of treatments.

Experiment 2: effects of manipulating stimulus duration. At the end of the 5-week withdrawal period, and continuing through all subsequent experiments, rats were run on the 5 -choice serial reaction time test task with the standard stimulus duration of $1 \mathrm{~s}$, for 5 days per week. In this experiment, performance was measured at a number of different stimulus durations. On each of five test sessions one of five different stimulus durations $(2,1,0.5,0.25$ and $0.125 \mathrm{~s}$ ) was in effect for the full session. The order of stimulus presentations was counterbalanced as far as possible with approximately equal numbers of subjects run at each duration on each day. Test sessions occurred on 
Tuesdays and Fridays; on intervening days the standard session with a $1 \mathrm{~s}$ stimulus duration was in effect. Testing occurred in the sixth and seventh weeks after cessation of amphetamine treatment.

Experiment 3: effects of a variable inter-trial interval. This experiment involved examining performance on the 5 -choice serial reaction time test when the standard $5 \mathrm{~s}$ ITI was changed to a variable ITI within a session. The task was exactly as for the sensitization and withdrawal phases except that the ITI was variable. Four intervals were used: 3.5, 5.5, 7.5, and $9.5 \mathrm{~s}$. Over the course of the session these intervals were presented randomly for a maximum of 25 presentations each. Testing occurred in the eighth week after cessation of amphetamine treatment.

Experiment 4: effects of intra-PFC injections of SKF38393. Following Experiment 3, rats underwent surgery for implantation of cannulae in the medial prefrontal cortex. After a 7-day recovery period testing on the behavioral task resumed. After a further 10 days of stable responding performance on the 5-choice serial reaction time was measured following infusions of $0.06 \mu \mathrm{g}$ of the dopamine D1 agonist SKF38393 HCl (Sigma-RBI, Oakville, ON), or its vehicle (saline), into the mPFC. The effects of these infusions were determined twice, once with a stimulus duration of $1 \mathrm{~s}$, and once with a stimulus duration of $0.25 \mathrm{~s}$. Thus, each rat was tested four times following all combinations of SKF38393 or vehicle, with each of the two stimulus durations. Test combinations were given in a counterbalanced order separated by a minimum of $72 \mathrm{~h}$. On intervening week-days rats were run as usual with a stimulus duration of $1 \mathrm{~s}$. Testing occurred in the 11th and 12th weeks after cessation of amphetamine treatment.

For the microinfusions, each rat was lightly restrained by hand, the obdurators were removed and a stainless-steel injector was inserted into the guide cannula. A volume of $0.5 \mu \mathrm{l}$ was infused over $2 \mathrm{~min}$, and the injector left in place for a further $2 \mathrm{~min}$. The obdurators were replaced and the rat was placed in the test chamber; the test session began immediately. Before any drug infusions all rats were extensively familiarized with the handling procedure used for the microinjections. After histological verification of injection sites one animal was excluded from the salinetreated group.

Experiment 5: effects of an amphetamine challenge on locomotor activity. Beginning approximately 13 weeks after the final injection of amphetamine rats were habituated to the locomotor activity testing cages for $2 \mathrm{~h}$ on each of three consecutive days. On the test day all rats were injected with $0.5 \mathrm{mg} / \mathrm{kg}$ amphetamine immediately before being placed in the activity cages. The number of photocell interruptions was recorded over the next $60 \mathrm{~min}$.

\section{Statistical Analyses}

Data were analyzed by $t$-tests (baseline data for Experiment 1 , Experiment 5), or by two-way analysis of variance (Experiments 1, 2, and 3) or three-way analysis of variance (Experiment 4). Where appropriate, a significant three-way interaction was further analyzed by tests of simple interactions. Post hoc comparisons between means were made using Tukey's test.

\section{RESULTS}

Before testing rats were assigned to receive amphetamine or saline treatment based on baseline levels of performance. Accordingly there were no significant differences between the two groups on any measure of performance at baseline (all $p>0.1$; see Figures 1 and 2).

\section{Experiment 1: Effects of Amphetamine Sensitization and Withdrawal}

Sensitization phase. Figures 1 and 2 illustrate performance of saline and amphetamine-treated rats on the 5-choice serial reaction time test for the 5 week drug treatment period, and the subsequent 5-week withdrawal period. During the 5 weeks of amphetamine exposure accuracy of responding was unaffected by amphetamine; neither the main effect of treatment nor the interaction between treatment and week being significant $(p>0.2)$. The proportion of trials on which responses were omitted (\% omissions) was significantly increased in the amphetamine-treated group, as reflected by the significant main effect of treatment $(\mathrm{F}(1,14)=13.62, p<0.01)$ and the interaction between treatment and week $(F(4,56)=2.86$,
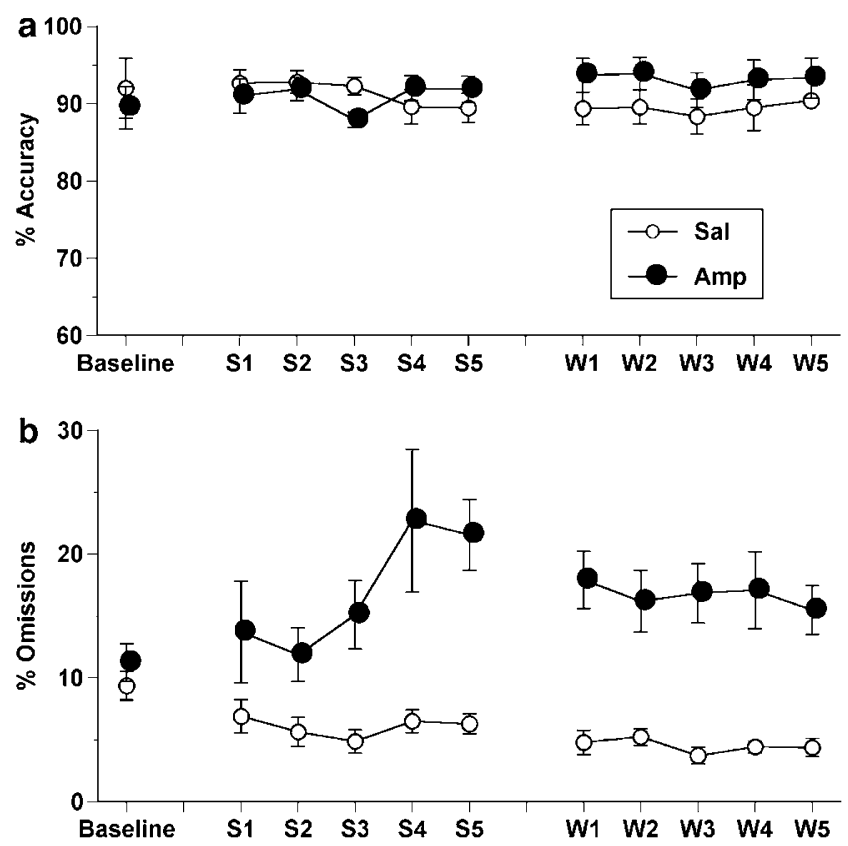

Figure I Performance on the 5-choice serial reaction time for rats injected with saline (Sal) or amphetamine (Amp). The graphs depict (a) \% accuracy of responding, and (b) the percentage of trials on which animals failed to respond (omissions). Performance was measured at baseline, prior to any treatment, through 5 weeks of the sensitization regimen (SI-S5) and for a further 5 weeks after withdrawal of treatment (WI-5). Drug injections were administered on Monday, Wednesday, and Friday of each week; behavioural testing was conducted on Tuesday, Thursday and Saturday of each week. Symbols denote the averaged mean ( \pm SEM) weekly performance of rats receiving saline $(n=7)$ or the escalating dose regimen of amphetamine $(n=9)$. 
$p<0.05)$. The latency to make a correct response, the latency to collect the reinforcer as well as the number of premature responses were not affected by amphetamine treatment (main effects and interactions all $p>0.1$ ). The number of perseverative responses was higher in the amphetamine-treated group $(\mathrm{F}(1,14)=23.07, p<0.001)$. Although the amphetamine $\times$ week interaction was not significant $(\mathrm{F}(4,56)=1.23, \quad p>0.29)$, post hoc testing confirmed that the group difference was significant on weeks $2-5(p<0.01)$.

Withdrawal phase. During the 5 weeks after cessation of amphetamine treatment amphetamine-treated rats showed a modest but nonsignificant increase in accuracy of responding $(\mathrm{F}(1,14)=2.02, p>0.05)$. This was accompanied by a significant increase in the percentage of omitted responses $(\mathrm{F}(1,14)=33.1, p<0.001)$ that was sustained over the 5 weeks of testing. Amphetamine treatment did not alter latency to respond, latency to collect reinforcement, or premature responding (all $p$-values for main effects and interactions $>0.15$ ). Perseverative responding was slightly increased in amphetamine-treated rats $(\mathrm{F}(4,56)=9.03$, $p<0.01)$.
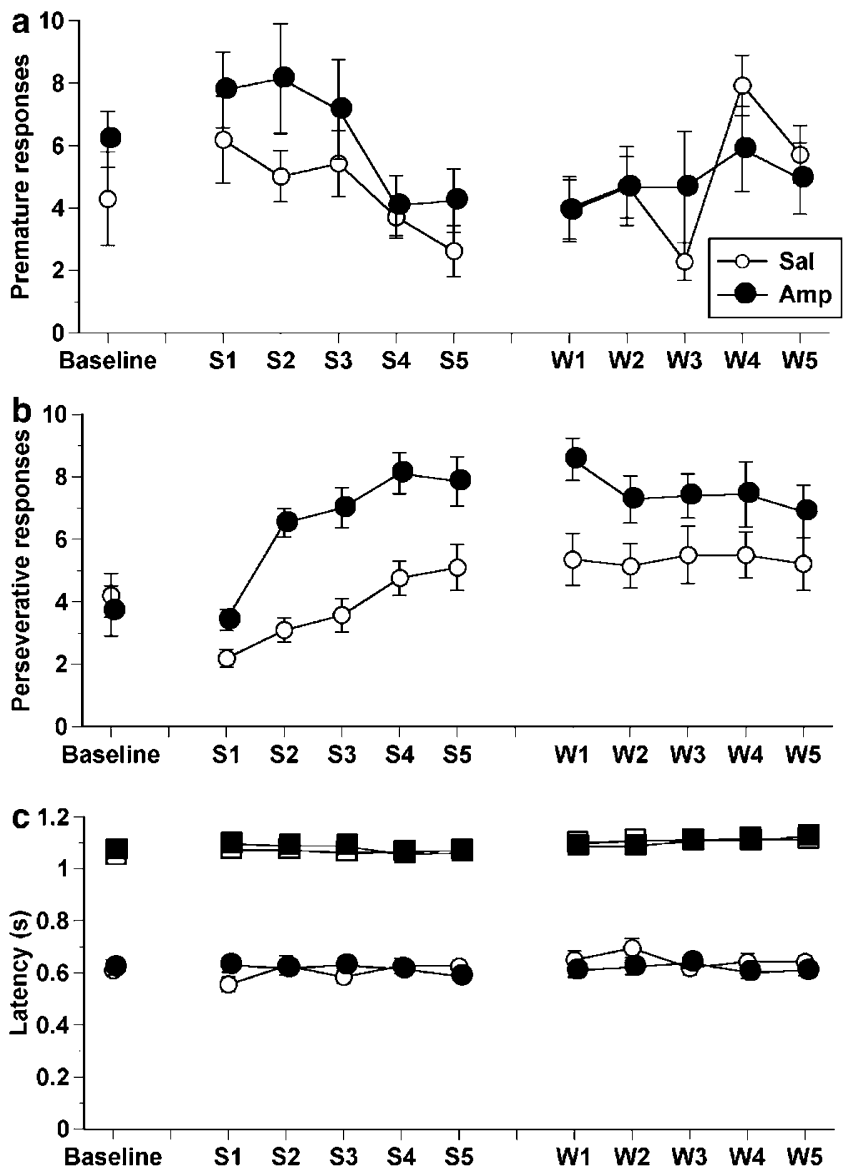

Figure 2 These figures show (a) the number of premature responses, (b) the number of perseverative responses, and (c) response (circles) and reinforcer latencies (squares) (s) for rats treated with saline (Sal) or amphetamine (Amp) and performing the 5-choice serial reaction time test. Open symbols = saline; closed symbols = amphetamine. Procedural details are the same as described in the legend to Figure I.

\section{Experiment 2: Effects of Manipulating Stimulus Duration}

As shown in Figure 3 reducing the stimulus duration reduced accuracy of responding $(\mathrm{F}(4,56)=138.0, p<0.001)$. Compared to controls amphetamine-treated rats showed a greater reduction in accuracy $(\mathrm{F}(1,14)=76.67)$, that varied as a function of stimulus duration $(\mathrm{F}(4,56)=16.11$, $p<0.0001)$. Accuracy was significantly lower in amphetamine-exposed rats compared to controls at the 0.5, 0.25 and $0.125 \mathrm{~s}$ stimulus durations. The proportion of trials on which omissions occurred increased as the stimulus duration was reduced $(F(4,56)=28.69, p<0.001)$. The percentage of omitted trials was also increased by prior amphetamine exposure $(\mathrm{F}(1,14)=80.4, p<0.001)$. The interaction between amphetamine treatment and stimulus duration was not significant; however, post hoc comparisons revealed that amphetamine-treated rats were significantly different from controls at stimulus durations of $1 \mathrm{~s}$ and less, but not at $2 \mathrm{~s}$. Levels of premature responding increased as the stimulus duration was reduced $(F(4,56)=3.47$,
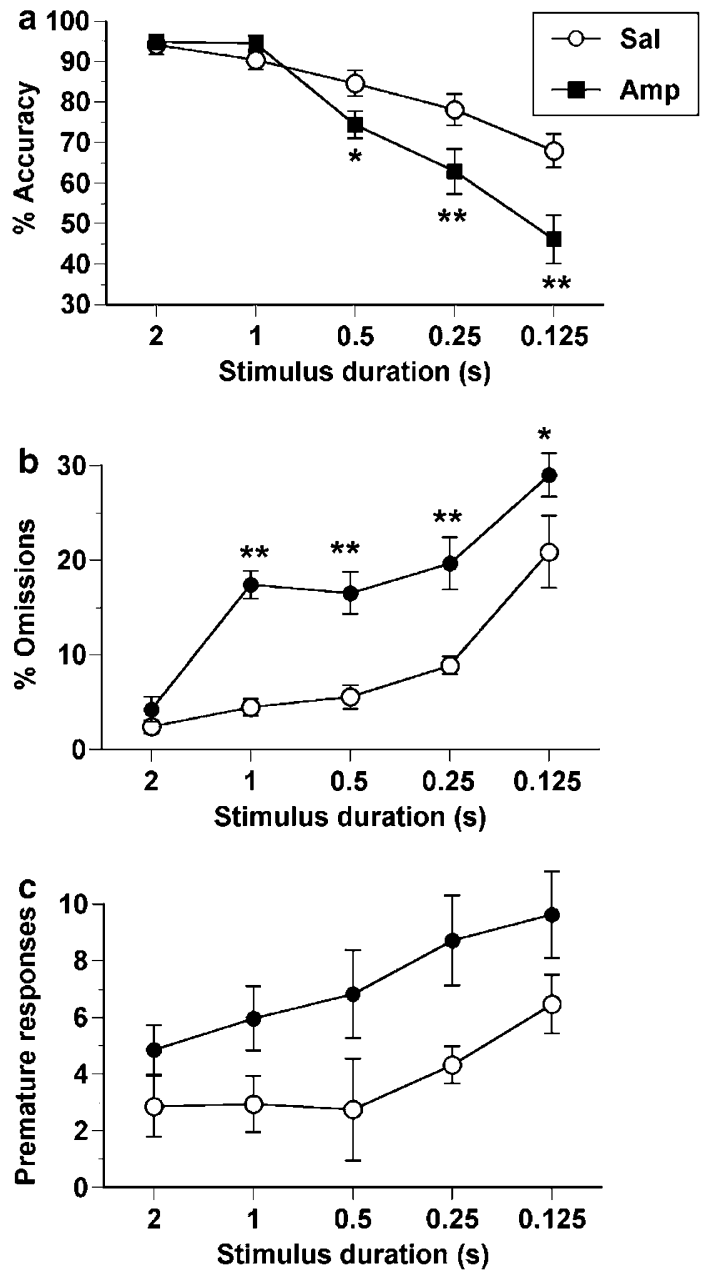

Figure 3 The effects of manipulating stimulus duration on (a) \% accuracy, (b) \% omissions and (c) number of premature responses for rats previously treated with saline (Sal) or amphetamine (Amp). Each stimulus duration was tested in a separate session. Testing occurred in the 6th and 7th weeks after cessation of amphetamine treatment. * * *** $p<0.05,0.0$ I compared to Sal condition. 
$p<0.003)$; the overall main effect of amphetamine treatment was significant $(\mathrm{F}(1,14)=12.07, p<0.01)$ but post hoc tests showed that these animals were significantly higher than controls only at the 0.25 and $0.125 \mathrm{~s}$ durations. No effects of amphetamine or stimulus duration were found for measures of perseverative responses, response latency or latency to collect the reinforcer (all $p>0.2$; data not shown).

\section{Experiment 3: Effects of Variable ITIs}

For each dependent variable performance was analyzed both as a function of the ITI (using a $2 \times 4$ ANOVA), and as a total collapsed across ITIs. The data are shown in Figure 4. Analysis of accuracy scores revealed only a main effect
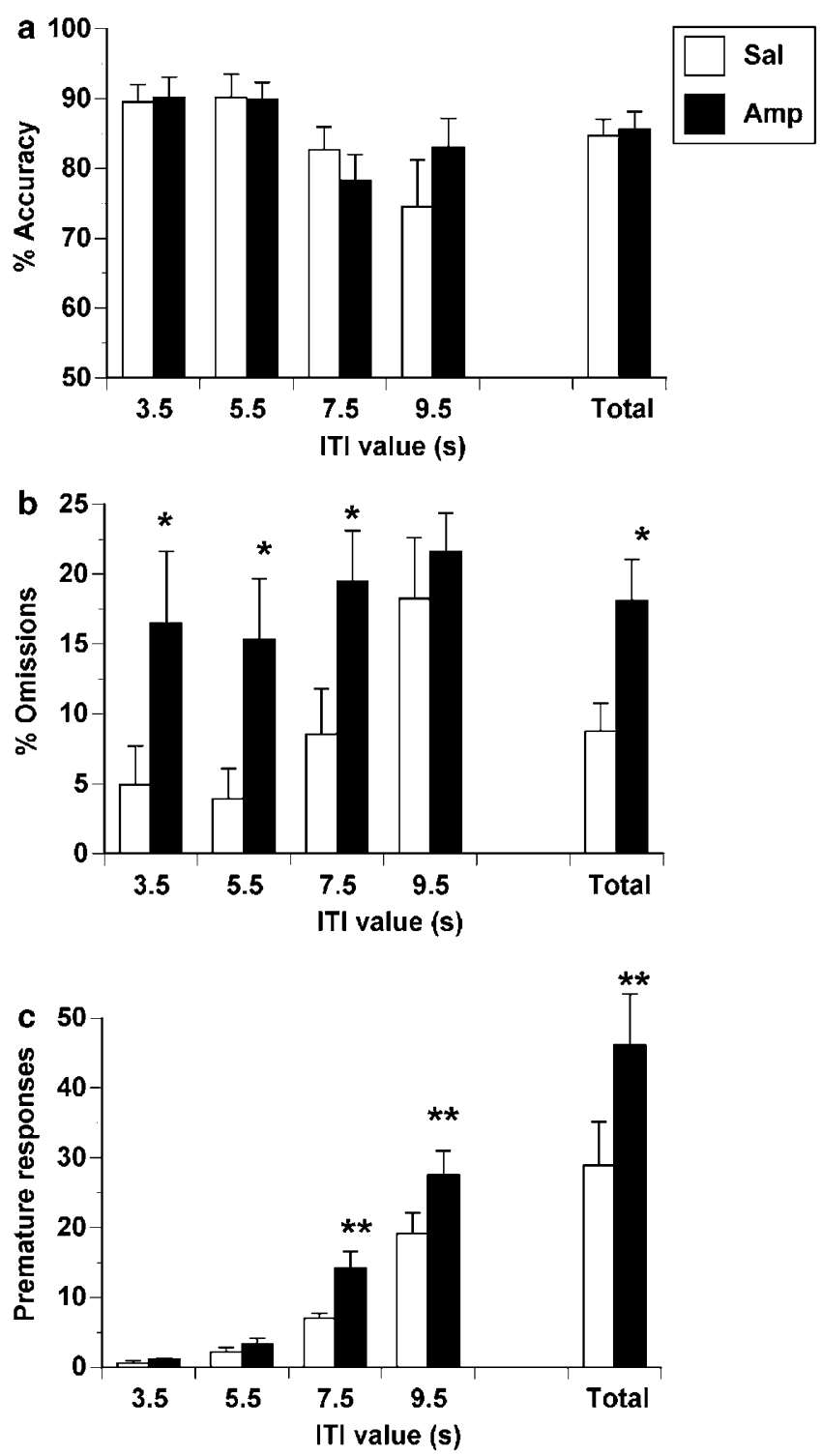

Figure 4 The effects of a within session variable inter-trial interval (3.5, 5.5, 7.5, and $9.5 \mathrm{~s}$ ) on (a) \% accuracy, (b) \% omissions and (c) The number of premature responses for saline (Sal) and amphetamine (Amp) treated rats. For each measure bars represent the average mean ( \pm SEM) value at each ITI, as well as for the whole session (Total). Testing occurred in the 8th week after cessation of amphetamine treatment. $* * * * * 0.05,0.0$ I compared to Sal condition. of ITI $(F(3,42)=6.22, p<0.001)$ reflecting the fact that performance declined slightly at the longest two ITIs. On the measure of omissions, amphetamine-sensitized rats showed an overall higher degree of omissions $(\mathrm{F}(1,14)=6.03, p<0.03)$; omissions tended to increase with increasing ITI value $(\mathrm{F}(3,42)=4.21, p<0.02)$. The interaction between ITI and amphetamine treatment was not significant $(\mathrm{F}(3,42)=0.78, p>0.5)$; post hoc comparisons showed that amphetamine-treated rats made significantly more errors of omission compared to controls on trials with ITIs of 3.5, 5.5, and 7.5 s but not 9.5 s. Premature responses were significantly higher in amphetamine-treated rats $(\mathrm{F}(1,14)=8.53, p<0.02)$, and at longer ITIs $(\mathrm{F}(3,42)=$ $55.5, p<0.001)$. The interaction was not significant $(p>0.2)$ but post hoc comparisons showed that premature responding was higher for amphetamine-treated rats only at the 7.5 and $9.5 \mathrm{~s}$ ITIs. No significant main effects of amphetamine, or interactions between ITI and amphetamine were found on measures of perseverative responses, correct latency or reinforcer latency (data not shown).

\section{Experiment 4: Effects of Intra-PFC Injections of SKF38393}

Figure 5 shows that the cannulae placements for this experiment were distributed throughout the $\mathrm{MPFC}$, at the level of the prelimbic and infralimbic regions.

The results of this experiment are shown in Figure 6. For the measure of response accuracy the main effects of stimulus duration $(\mathrm{F}(1,13)=95.2, p<0.001)$, and SKF38393 treatment $(\mathrm{F}(1,13)=108.1, \quad p<0.001) \quad$ were significant but the main effects of amphetamine treatment was not
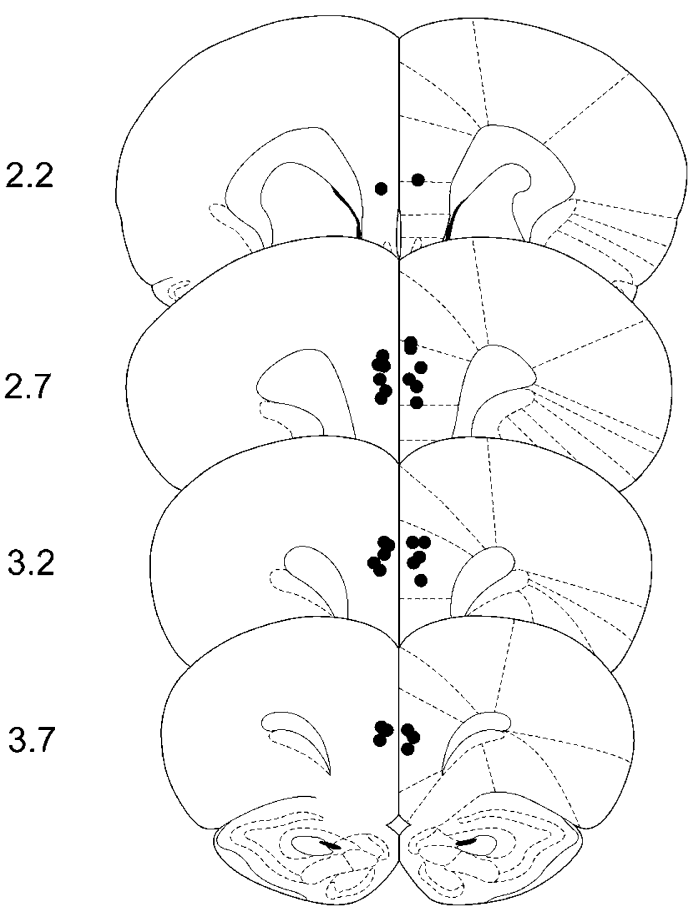

Figure 5 Schematic reconstruction of injection sites for rats used in Experiment 4. Sections are adapted from Paxinos and Watson (1998) at 3.7, 3.2, 2.7, and $2.2 \mathrm{~mm}$ anterior to bregma. The number of sites depicted is lower than the number of subjects used because of some overlap of sites. 

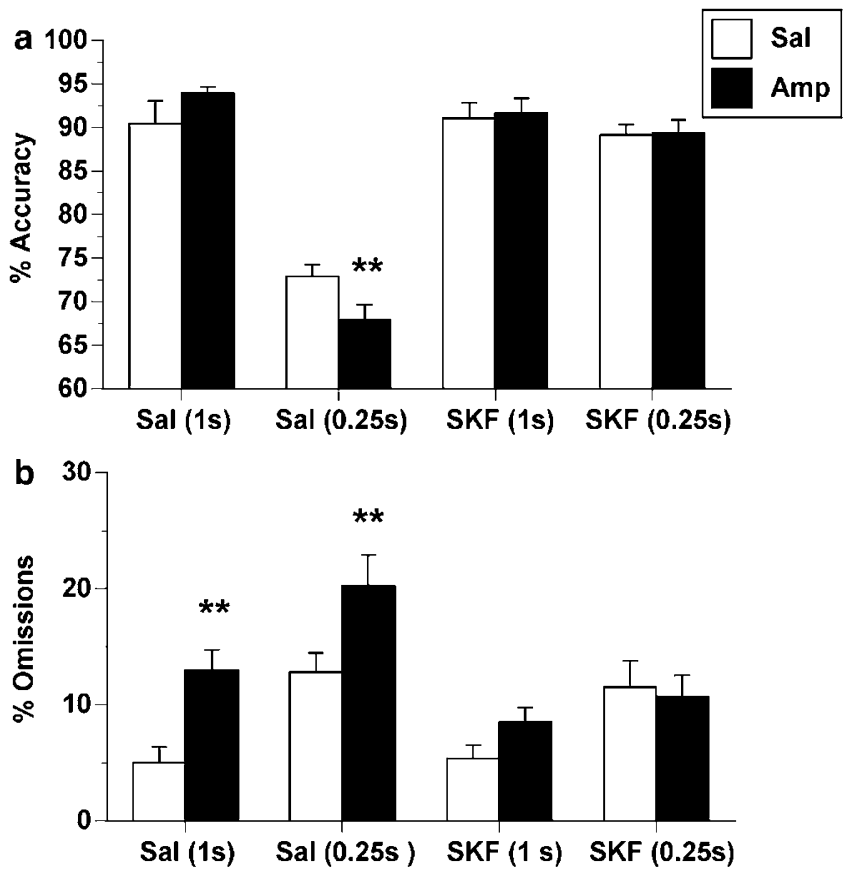

Figure 6 The effects of infusing SKF38393 (SKF; $0.06 \mu \mathrm{g}$ ) or saline into the PFC of saline (Sal; $n=6$ ) or amphetamine (Amp; $n=9$ ) treated rats performing the 5-choice serial reaction time test with stimulus durations of I and 0.25 s. (a) Shows effects on \% accuracy, and (b) shows effects on \% omissions. All rats were tested four times under all combinations of SKF38393 and saline, and I and $0.25 \mathrm{~s}$ stimulus duration. Testing occurred in the IIth and 12th weeks after cessation of amphetamine treatment. *** $p<0.0$ l compared to Sal condition at the same stimulus duration.

$(\mathrm{F}(1,13)=1.31, p>0.2)$. The overall three-way interaction between amphetamine treatment, stimulus duration and SKF38393 treatment was significant $(\mathrm{F}(1,13)=4.8$, $p<0.05)$. Analysis of simple interactions revealed that the interaction between amphetamine treatment and stimulus duration was significant following infusions of saline $(F(1,13)=7.66, \quad p<0.02)$ but not SKF38393 $(\mathrm{F}(1,13)=1.27, p>0.2)$ into the PFC. Thus, reducing the stimulus duration from 1 to $0.25 \mathrm{~s}$ reduced accuracy of responding, and this effect was enhanced in amphetaminetreated rats. These effects were observed only in rats infused with saline into the PFC. SKF38393 infused into the PFC eliminated the reduction in accuracy due to both amphetamine treatment and to reducing the stimulus duration.

For percentage omissions amphetamine-treated rats tended to show a higher incidence of omissions $(\mathrm{F}(1,13)=7.11, p<0.02)$, whereas SKF38393 tended to reduce omissions $(\mathrm{F}(1,13)=10.05, p<0.01)$. The interaction between amphetamine and SKF38393 was significant $(\mathrm{F}(1,13)=7.63, p<0.02)$. This interaction reflects the fact that while amphetamine enhanced omissions relative to control animals this effect occurred only following saline infusions into the PFC, and not when SKF38393 was injected into this area.

For measures of premature responding, perseverative responding, correct response latency and reinforcer latency there were no consistent effects of amphetamine treatment, SKF38393 treatment or interactions between the two factors (all $p>0.2$; data not shown).
Experiment 5: Effects of an Amphetamine Challenge on Locomotor Activity

Rats treated with the sensitizing regimen of amphetamine recorded $1737( \pm 211)$ photocell counts over $1 \mathrm{~h}$ following a challenge with $0.5 \mathrm{mg} / \mathrm{kg}$ amphetamine. Control rats recorded 535 ( \pm 75.8$)$ counts following such a challenge. This difference was highly significant $\left(t_{13}=4.56, p<0.001\right)$.

\section{GENERAL DISCUSSION}

Two main findings emerged from this study. Firstly, a regimen of amphetamine treatment that resulted in sensitization to the locomotor stimulant effects of amphetamine impaired visual attention, and this effect persisted for many weeks beyond cessation of the drug treatment. Secondly, the deficits found in amphetamine-treated rats were reversed by infusing the dopamine D1 receptor agonist SKF383893 into the mPFC. This manipulation also prevented the decline in accuracy of responding resulting from a reduced duration of the target stimulus.

During the period in which amphetamine was administered and withdrawn, the primary behavioral effect in amphetamine-treated rats was a consistent increase in the number of trials on which animals failed to respond. The increase in omissions persisted through 5 weeks of withdrawal and was also apparent beyond that time point in all of the subsequent individual experiments, including ones in which the stimulus duration was altered and the ITI was varied. None of the other measures of task performance was affected in such an obvious or consistent fashion. In particular, accuracy of responding at least under basal task conditions of the $1 \mathrm{~s}$ stimulus duration, was not altered by amphetamine treatment. However, accuracy of responding was impaired in amphetamine-treated rats under conditions of reduced stimulus duration.

The increased incidence of omissions by amphetaminetreated rats likely reflects a primary attentional deficit, rather than a nonspecific performance impairment, for several reasons. Firstly, lengthening the stimulus duration from 1 to $2 \mathrm{~s}$ eliminated the effect in amphetamine-treated rats who responded on almost all trials with a high degree of accuracy. Secondly, speed of responding to the light stimulus, as well as latency to collect the reinforcer, were not altered by amphetamine treatment; this suggests that increases in omissions cannot be attributed to alterations in basic motor or motivational processes. Thirdly, as the stimulus duration was progressively reduced the proportion of omissions increased, with sensitized rats continuing to show substantially elevated levels of omissions compared to controls. At the same time, accuracy of responding declined in all animals but this effect was more pronounced in amphetamine-sensitized rats. Presumably a reduction in stimulus duration increases the difficulty of the task, because of increased demands on attentional resources, and this serves to further reveal an attentional deficit in the amphetamine-sensitized rats.

No consistent effects of amphetamine treatment were found on measures of perseverative or premature responding; again this is consistent with the lack of effect of self-administered amphetamine on these measures (Dalley et al, 2005). On occasion, significant differences between 
amphetamine-treated and control rats were found. Amphetamine-treated rats showed a statistically significant increase in perseverative responding during, and after, drug treatment. However, this effect was somewhat small (less than 10 responses per session), and did not persist into subsequent experiments. Premature responding, a behavior that is increased by lesions of several cortical areas (anterior cingulate, orbitofrontal and infralimbic cortices) (Chudasama et al, 2003; Muir et al, 1996) was not consistently affected by amphetamine treatment on the basal task. Again, however, basal levels of premature responding were low in comparison to other published findings. One manipulation that elevates premature responding is the use of variable ITIs. In the present study longer ITIs increased premature responding, and this effect was enhanced in amphetamine-treated rats. Thus, under some experimental conditions amphetamine-sensitized rats appear to have some difficulties with inhibitory control.

In a previous study, rats were given six cycles of five daily periods (up to $8 \mathrm{~h}$ ) of amphetamine self-administration followed by 9 days of testing on the 5 -choice serial reaction time test (Dalley et al, 2005). As in the present study, these amphetamine-exposed rats showed reduced accuracy of responding, and increased omission errors. These effects generally lasted for the first few days of each attentional testing cycle, and were absent after a 2-month withdrawal period. This contrasts with the long-lasting nature of the deficits seen in the present experiment. Procedural differences between the two studies include the use of self-administered $v s$ experimenter administered drug, route of injection (i.v. vs i.p.), multiple $v s$ single dosing within a day, and differences in the total amount drug given to the animals. As in our earlier work (Fletcher et al, 2005; Tenn et al, 2003, 2005) rats receiving intermittent, escalating dosing with amphetamine became sensitized to the locomotor stimulant effect of amphetamine. Dalley et al (2005) suggested that in their study such sensitization may not have developed, based partly on the fact that rats selfadministering amphetamine showed a blunted, rather than enhanced, response to an amphetamine challenge in the 5choice serial reaction time test, and partly on the basis that stimulant sensitization does not seem to develop with long duration access to self-administered stimulants (Ben-Shahar et al, 2004). It is likely then that a major contributor to the different long-term outcomes of these two regimens of amphetamine on attention relates to different neuroadaptive changes produced by the different schedules of drug exposure. However, at the present time the precise nature of those adaptive changes is not clear.

The mechanism by which amphetamine exposure disrupts sustained attention is not known, although several candidate mechanisms can be proposed. Rats in the amphetamine-sensitized state have enhanced functioning of the mesolimbic dopamine system (Paulson and Robinson, 1995; Robinson, 1984; Robinson and Becker, 1986). In the 5-choice serial reaction time test amphetamine infused into the nucleus accumbens (Cole and Robbins, 1987, 1989) affects primarily speed of responding rather than accuracy or omissions and so it is unlikely that a sensitized mesolimbic DA system mediates the deficits observed in amphetamine-treated rats. In an attentional set-shifting task amphetamine-sensitized rats exhibited deficits in making discriminations based on an extra-dimensional shift, and on reversal learning (Fletcher et al, 2005). Such deficits are produced also by lesions to the mPFC (Birrell and Brown, 2000) and orbitofrontal cortex (McAlonan and Brown, 2003) respectively, and prior amphetamine exposure induces morphological changes in these areas (Crombag et al, 2005). Excitotoxic lesions to subregions of the mPFC reduce accuracy and enhance errors of omission (Muir et al, 1996; Passetti et al, 2002), while damage to the orbitofrontal cortex enhances errors of omission (Chudasama et al, 2003) on the 5-choice serial reaction time test. Taken together these convergent lines of evidence suggest that attentional deficits resulting from the amphetamine-induced sensitized state may result from altered functioning of these frontal cortical areas.

What is not known is the nature of the changes induced in cortical functioning, induced by amphetamine although alterations in many aspects of PFC activity and function have been described. These include morphological changes in pyramidal neurons (Crombag et al, 2005; Robinson and Kolb, 1997), altered expression of glutamate receptors (Lu et al, 1999; Lu and Wolf, 1999), reduced patterns of c-fos induction after an amphetamine challenge (Feldpausch et $a l, 1998)$, and blunted dopamine release within the mPFC in response to amphetamine (Hedou et al, 2001; Vanderschuren et al, 1999) or cocaine (Sorg et al, 1997). Repeated amphetamine treatment also blunts the subsequent responsivity of PFC neurons to dopamine itself and to D1 agonists (Peterson et al, 2000, 2006). These results combined with the finding that the D1 receptor agonist SKF38393 ameliorates the attentional deficits in amphetamine-treated rats suggest that impaired cortical dopamine D1-receptor mediated neurotransmission might underlie the attentional deficits observed in rats previously exposed to amphetamine.

Amphetamine exposure disrupts sustained attention in a discrete trials, two-lever task in which rats discriminate between a signal vs no signal (Deller and Sarter, 1998; Martinez et al, 2005). These authors suggest that altered cholinergic function mediates the deficits in amphetamine exposed animals (Deller and Sarter, 1998; Martinez et al, 2005). Given the quite different natures of the behavioral tasks and the sensitizing regimens of amphetamine it is difficult to make direct comparisons between our study and those of Sarter and co-workers. However, it is interesting that several studies (Lehmann et al, 2003; Muir et al, 1994, 1993) have shown that cortical acetylcholine depletion impairs attentional performance in the 5-choice serial reaction time test in a manner similar to amphetamine exposure.

Previous work has shown that activation of prefrontal D1 receptors, using SKF38393, enhanced accuracy in the 5 -choice serial reaction time test, but only in poorly performing animals (Granon et al, 2000). The present results showing that intra-PFC SKF38393 enhances attentional performance extend this finding in two ways. Firstly, SKF38393 reversed the attentional deficits displayed by amphetamine-treated rats. This result is consistent with our previous finding that SKF38393 reverses an attentional setshifting deficit in amphetamine-treated rats. Secondly, in control rats SKF38393 completely reversed the deficits in attentional performance that resulted from lowering the 
stimulus duration from 1 to $0.25 \mathrm{~s}$. Although SKF38393 is an agonist at D1 receptors it shows some affinity for $5-\mathrm{HT}_{2 \mathrm{C}}$, though not $5-\mathrm{HT}_{2 \mathrm{~A}}$ receptors, as well as alpha-2 adrenergic receptors (Briggs et al, 1991; Neumeyer et al, 2003). Manipulations of 5-HT systems affect primarily premature responding (Higgins et al, 2003; Passetti et al, 2003), while alpha-2 adrenergic ligands do not affect measures of choice accuracy (Sirvio et al, 1994), suggesting that actions at 5-HT and adrenergic receptors are not responsible for the reversal of attentional deficits by SKF38393. The fact that SKF38393 improved attentional performance following local PFC infusion is consistent with the hypothesis that the amphetamine-induced deficits may result from altered PFC function. These data do show that the amphetamine-induced deficit in attentional function is reversible, and also add to a growing body of evidence that $\mathrm{D} 1$ receptors in the $\mathrm{PFC}$ are important for cognitive function across a variety of domains, and not just in working memory.

Schizophrenia is characterized by a variety of cognitive deficits (eg, Keefe, 2001; Nuechterlein et al, 2004). Attention/vigilance, reasoning and problem solving, and working memory are 3 key domains in which cognition is impaired in schizophrenia (Green et al, 2004; Nuechterlein et al, 2004). The intermittent, escalating dose regimen of amphetamine used here produces a long-term deficit in attentional set-shifting (Fletcher et al, 2005), which may reflect impaired reasoning and problem solving skills (Nuechterlein et al, 2005). The fact that this same regimen of amphetamine exposure disrupts attention in the 5-choice serial reaction time test shows that the amphetamineinduced sensitized state potentially affects cognition across different domains. Such findings suggest that the amphetamine-induced sensitized state may be a useful model for the cognitive deficit state of schizophrenia. The findings that impaired set-shifting, and poor attentional performance resulting from prior amphetamine exposure are prevented by SKF38393 infused into the mPFC shows that pharmacological reversal of cognitive deficits can be detected in this model. Additionally, the results obtained with this D1 receptor agonist add further evidence to the case for the D1 receptor as a target for pharmacological strategies for improving cognition in schizophrenia (Castner et al, 2004; Goldman-Rakic et al, 2004).

\section{ACKNOWLEDGEMENTS}

This work was supported by a special initiative grant from the Ontario Mental Health Foundation. CT was supported by a Research Fellowship from the OMHF and SK was supported by a CRC Chair.

\section{REFERENCES}

Abi-Dargham A, Gil R, Krystal J, Baldwin RM, Seibyl JP, Bowers M et al (1998). Increased striatal dopamine transmission in schizophrenia: confirmation in a second cohort. Am J Psychiatry 155: 761-767.

Ben-Shahar O, Ahmed SH, Koob GF, Ettenberg A (2004). The transition from controlled to compulsive drug use is associated with a loss of sensitization. Brain Res 995: 46-54.
Birrell JM, Brown VJ (2000). Medial frontal cortex mediates perceptual attentional set shifting in the rat. J Neurosci 20: 4320-4324.

Briggs CA, Pollock NJ, Frail DE, Paxson CL, Rakowski RF, Kang $\mathrm{CH}$ et al (1991). Activation of the 5-HT1C receptor expressed in Xenopus oocytes by the benzazepines SCH 23390 and SKF 38393. Br J Pharmacol 104: 1038-1044.

Castner SA, Goldman-Rakic PS, Williams GV (2004). Animal models of working memory: insights for targeting cognitive dysfunction in schizophrenia. Psychopharmacology (Berlin) 174: 111-125.

Castner SA, Vosler PS, Goldman-Rakic PS (2005). Amphetamine sensitization impairs cognition and reduces dopamine turnover in primate prefrontal cortex. Biol Psychiatry 57: 743-751.

Chudasama Y, Passetti F, Rhodes SE, Lopian D, Desai A, Robbins TW (2003). Dissociable aspects of performance on the 5-choice serial reaction time task following lesions of the dorsal anterior cingulate, infralimbic and orbitofrontal cortex in the rat: differential effects on selectivity, impulsivity and compulsivity. Behav Brain Res 146: 105-119.

Cole BJ, Robbins TW (1987). Amphetamine impairs the discriminative performance of rats with dorsal noradrenergic bundle lesions on a 5-choice serial reaction time task: new evidence for central dopaminergic-noradrenergic interactions. Psychopharmacology (Berlin) 91: 458-466.

Cole BJ, Robbins TW (1989). Effects of 6-hydroxydopamine lesions of the nucleus accumbens septi on performance of a 5-choice serial reaction time task in rats: implications for theories of selective attention and arousal. Behav Brain Res 33: 165-179.

Crombag HS, Gorny G, Li Y, Kolb B, Robinson TE (2005). Opposite effects of amphetamine self-administration experience on dendritic spines in the medial and orbital prefrontal cortex. Cereb Cortex 15: 341-348.

Dalley JW, Theobald DE, Berry D, Milstein JA, Laane K, Everitt BJ et al (2005). Cognitive sequelae of intravenous amphetamine self-administration in rats: evidence for selective effects on attentional performance. Neuropsychopharmacology 30: 525-537.

Deller T, Sarter M (1998). Effects of repeated administration of amphetamine on behavioral vigilance: evidence for 'sensitized' attentional impairments. Psychopharmacology (Berlin) 137: 410-414.

Ellenbroek BA, Knobbout DA, Cools AR (1997). The role of mesolimbic and nigrostriatal dopamine in latent inhibition as measured with the conditioned taste aversion paradigm. Psychopharmacology (Berlin) 129: 112-120.

Feldpausch DL, Needham LM, Stone MP, Althaus JS, Yamamoto BK, Svensson KA et al (1998). The role of dopamine D4 receptor in the induction of behavioral sensitization to amphetamine and accompanying biochemical and molecular adaptations. J Pharmacol Exp Ther 286: 497-508.

Fletcher PJ, Tenn CC, Rizos Z, Lovic V, Kapur S (2005). Sensitization to amphetamine, but not PCP, impairs attentional set shifting: reversal by a D1 receptor agonist injected into the medial prefrontal cortex. Psychopharmacology (Berln) 183: 190-200.

Goldman-Rakic PS (1995). Cellular basis of working memory. Neuron 14: 477-485.

Goldman-Rakic PS, Castner SA, Svensson TH, Siever LJ, Williams GV (2004). Targeting the dopamine D1 receptor in schizophrenia: insights for cognitive dysfunction. Psychopharmacology (Berlin) 174: 3-16.

Granon S, Passetti F, Thomas KL, Dalley JW, Everitt BJ, Robbins TW (2000). Enhanced and impaired attentional performance after infusion of D1 dopaminergic receptor agents into rat prefrontal cortex. J Neurosci 20: 1208-1215.

Green MF, Nuechterlein KH, Gold JM, Barch DM, Cohen J, Essock $\mathrm{S}$ et al (2004). Approaching a consensus cognitive battery for clinical trials in schizophrenia: the NIMH-MATRICS 
conference to select cognitive domains and test criteria. Biol Psychiatry 56: 301-307.

Hedou G, Homberg J, Feldon J, Heidbreder CA (2001). Expression of sensitization to amphetamine and dynamics of dopamine neurotransmission in different laminae of the rat medial prefrontal cortex. Neuropharmacology 40: 366-382.

Higgins GA, Enderlin M, Haman M, Fletcher PJ (2003). The 5-HT2A receptor antagonist M100,907 attenuates motor and 'impulsive-type' behaviours produced by NMDA receptor antagonism. Psychopharmacology (Berlin) 170: 309-319.

Howes OD, McDonald C, Cannon M, Arseneault L, Boydell J, Murray RM (2004). Pathways to schizophrenia: the impact of environmental factors. Int J Neuropsychopharmacol 7(Suppl 1): S7-S13.

Jeanblanc J, Hoeltzel A, Louilot A (2002). Dissociation in the involvement of dopaminergic neurons innervating the core and shell subregions of the nucleus accumbens in latent inhibition and affective perception. Neuroscience 111: 315-323.

Jentsch JD, Olausson P, De La Garza II R, Taylor JR (2002). Impairments of reversal learning and response perseveration after repeated, intermittent cocaine administrations to monkeys. Neuropsychopharmacology 26: 183-190.

Jones MW (2002). A comparative review of rodent prefrontal cortex and working memory. Curr Mol Med 2: 639-647.

Joseph MH, Peters SL, Moran PM, Grigoryan GA, Young AM, Gray JA (2000). Modulation of latent inhibition in the rat by altered dopamine transmission in the nucleus accumbens at the time of conditioning. Neuroscience 101: 921-930.

Keefe RSE (2001). Neurocognition. In Breier A, Tran PV, Herrera $\mathrm{JM}$, Tollefson GD, Bymaster FP (eds). Current Issues in the Psychopharmacology of Schizophrenia. Lippincott, Williams \& Wilkins: Philadelphia. pp 192-205.

Kodsi MH, Swerdlow NR (1994). Quinolinic acid lesions of the ventral striatum reduce sensorimotor gating of acoustic startle in rats. Brain Res 643: 59-65.

Laruelle M (2000). The role of endogenous sensitization in the pathophysiology of schizophrenia: implications from recent brain imaging studies. Brain Res Brain Res Rev 31: 371-384.

Laruelle M, Abi-Dargham A, Gil R, Kegeles L, Innis R (1999). Increased dopamine transmission in schizophrenia: relationship to illness phases. Biol Psychiatry 46: 56-72.

Lehmann O, Grottick AJ, Cassel JC, Higgins GA (2003). A double dissociation between serial reaction time and radial maze performance in rats subjected to 192 IgG-saporin lesions of the nucleus basalis and/or the septal region. Eur J Neurosci 18: 651-666.

Lieberman JA, Kane JM, Alvir J (1987). Provocative tests with psychostimulant drugs in schizophrenia. Psychopharmacology (Berlin) 91: 415-433.

Lieberman JA, Sheitman BB, Kinon BJ (1997). Neurochemical sensitization in the pathophysiology of schizophrenia: deficits and dysfunction in neuronal regulation and plasticity. Neuropsychopharmacology 17: 205-229.

Lu W, Monteggia LM, Wolf ME (1999). Withdrawal from repeated amphetamine administration reduces NMDAR1 expression in the rat substantia nigra, nucleus accumbens and medial prefrontal cortex. Eur J Neurosci 11: 3167-3177.

Lu W, Wolf ME (1999). Repeated amphetamine administration alters AMPA receptor subunit expression in rat nucleus accumbens and medial prefrontal cortex. Synapse 32: $119-131$

Martinez V, Parikh V, Sarter M (2005). Sensitized attentional performance and Fos-immunoreactive cholinergic neurons in the basal forebrain of amphetamine-pretreated rats. Biol Psychiatry 57: 1138-1146.

McAlonan K, Brown VJ (2003). Orbital prefrontal cortex mediates reversal learning and not attentional set shifting in the rat. Behav Brain Res 146: 97-103.
Muir JL, Everitt BJ, Robbins TW (1994). AMPA-induced excitotoxic lesions of the basal forebrain: a significant role for the cortical cholinergic system in attentional function. J Neurosci 14: 2313-2326.

Muir JL, Everitt BJ, Robbins TW (1996). The cerebral cortex of the rat and visual attentional function: dissociable effects of mediofrontal, cingulate, anterior dorsolateral, and parietal cortex lesions on a five-choice serial reaction time task. Cereb Cortex 6: 470-481.

Muir JL, Page KJ, Sirinathsinghji DJ, Robbins TW, Everitt BJ (1993). Excitotoxic lesions of basal forebrain cholinergic neurons: effects on learning, memory and attention. Behav Brain Res 57: 123-131.

Murphy CA, Fend M, Russig H, Feldon J (2001). Latent inhibition, but not prepulse inhibition, is reduced during withdrawal from an escalating dosage schedule of amphetamine. Behav Neurosci 115: $1247-1256$.

Nelson LR, Ellison G (1978). Enhanced stereotypies after repeated injections but not continuous amphetamines. Neuropharmaco$\log y$ 17: 1081-1084.

Neumeyer JL, Kula NS, Bergman J, Baldessarini RJ (2003). Receptor affinities of dopamine D1 receptor-selective novel phenylbenzazepines. Eur J Pharmacol 474: 137-140.

Nuechterlein KH, Barch DM, Gold JM, Goldberg TE, Green MF, Heaton RK (2004). Identification of separable cognitive factors in schizophrenia. Schizophr Res 72: 29-39.

Nuechterlein KH, Robbins TW, Einat H (2005). Distinguishing separable domains of cognition in human and animal studies: what separations are optimal for targeting interventions? A summary of recommendations from breakout group 2 at the measurement and treatment research to improve cognition in schizophrenia new approaches conference. Schizophr Bull 31: 870-874.

Passetti F, Chudasama Y, Robbins TW (2002). The frontal cortex of the rat and visual attentional performance: dissociable functions of distinct medial prefrontal subregions. Cereb Cortex 12: $1254-1268$.

Passetti F, Dalley JW, Robbins TW (2003). Double dissociation of serotonergic and dopaminergic mechanisms on attentional performance using a rodent five-choice reaction time task. Psychopharmacology (Berlin) 165: 136-145.

Paulson PE, Robinson TE (1995). Amphetamine-induced timedependent sensitization of dopamine neurotransmission in the dorsal and ventral striatum: a microdialysis study in behaving rats. Synapse 19: 56-65.

Paxinos G, Watson C (1998). The Rat Brain in Stereotaxic Coordinates, 4th edn. Academic Press: Sydney.

Peterson JD, Wolf ME, White FJ (2000). Altered responsiveness of medial prefrontal cortex neurons to glutamate and dopamine after withdrawal from repeated amphetamine treatment. Synapse 36: 342-344.

Peterson JD, Wolf ME, White FJ (2006). Repeated amphetamine administration decreases D1 dopamine receptor-mediated inhibition of voltage-gated sodium currents in the prefrontal cortex. J Neurosci 26: 3164-3168.

Post RM (1980). Intermittent $v s$ continuous stimulation: effect of time interval on the development of sensitization or tolerance. Life Sci 26: 1275-1282.

Pratt WE, Mizumori SJ (2001). Neurons in rat medial prefrontal cortex show anticipatory rate changes to predictable differential rewards in a spatial memory task. Behav Brain Res 123: 165-183.

Robbins TW (2002). The 5-choice serial reaction time task: behavioural pharmacology and functional neurochemistry. Psychopharmacology (Berlin) 163: 362-380.

Robinson TE (1984). Behavioral sensitization: characterization of enduring changes in rotational behavior produced by intermittent injections of amphetamine in male and female rats. Psychopharmacology (Berlin) 84: 466-475. 
Robinson TE, Becker JB (1986). Enduring changes in brain and behavior produced by chronic amphetamine administration: a review and evaluation of animal models of amphetamine psychosis. Brain Res 396: 157-198.

Robinson TE, Jurson PA, Bennett JA, Bentgen KM (1988). Persistent sensitization of dopamine neurotransmission in ventral striatum (nucleus accumbens) produced by prior experience with (+)-amphetamine: a microdialysis study in freely moving rats. Brain Res 462: 211-222.

Robinson TE, Kolb B (1997). Persistent structural modifications in nucleus accumbens and prefrontal cortex neurons produced by previous experience with amphetamine. J Neurosci 17: 8491-8497.

Russig H, Kovacevic A, Murphy CA, Feldon J (2003). Haloperidol and clozapine antagonise amphetamine-induced disruption of latent inhibition of conditioned taste aversion. Psychopharmacology (Berlin) 170: 263-270.

Russig H, Murphy CA, Feldon J (2002). Clozapine and haloperidol reinstate latent inhibition following its disruption during amphetamine withdrawal. Neuropsychopharmacology 26: 765-777.

Sato M, Numachi Y, Hamamura T (1992). Relapse of paranoid psychotic state in methamphetamine model of schizophrenia. Schizophr Bull 18: 115-122.

Schoenbaum G, Saddoris MP, Ramus SJ, Shaham Y, Setlow B (2004). Cocaine-experienced rats exhibit learning deficits in a task sensitive to orbitofrontal cortex lesions. Eur J Neurosci 19: 1997-2002.

Sirvio J, Mazurkiewicz M, Haapalinna A, Riekkinen Jr P, Lahtinen H, Riekkinen Sr PJ (1994). The effects of selective alpha-2 adrenergic agents on the performance of rats in a 5-choice serial reaction time task. Brain Res Bull 35: 451-455.

Solomon PR, Staton DM (1982). Differential effects of microinjections of d-amphetamine into the nucleus accumbens or the caudate putamen on the rat's ability to ignore an irrelevant stimulus. Biol Psychiatry 17: 743-756.

Sorg BA, Davidson DL, Kalivas PW, Prasad BM (1997). Repeated daily cocaine alters subsequent cocaine-induced increase of extracellular dopamine in the medial prefrontal cortex. $J$ Pharmacol Exp Ther 281: 54-61.

Swerdlow NR, Mansbach RS, Geyer MA, Pulvirenti L, Koob GF, Braff DL (1990). Amphetamine disruption of prepulse inhibition of acoustic startle is reversed by depletion of mesolimbic dopamine. Psychopharmacology (Berlin) 100: 413-416.

Tenn CC, Fletcher PJ, Kapur S (2003). Amphetamine-sensitized animals show a sensorimotor gating and neurochemical abnormality similar to that of schizophrenia. Schizophr Res 64: 103-114.

Tenn CC, Kapur S, Fletcher PJ (2005). Sensitization to amphetamine, but not phencyclidine, disrupts prepulse inhibition and latent inhibition. Psychopharmacology (Berlin) 183: 190-200.

Ujike H (2002). Stimulant-induced psychosis and schizophrenia: the role of sensitization. Curr Psychiatry Rep 4: 177-184.

Vanderschuren LJ, Kalivas PW (2000). Alterations in dopaminergic and glutamatergic transmission in the induction and expression of behavioral sensitization: a critical review of preclinical studies. Psychopharmacology (Berlin) 151: 99-120.

Vanderschuren LJ, Schmidt ED, De Vries TJ, Van Moorsel CA, Tilders FJ, Schoffelmeer AN (1999). A single exposure to amphetamine is sufficient to induce long-term behavioral, neuroendocrine, and neurochemical sensitization in rats. J Neurosci 19: 9579-9586.

Wan FJ, Swerdlow NR (1996). Sensorimotor gating in rats is regulated by different dopamine-glutamate interactions in the nucleus accumbens core and shell subregions. Brain Res $\mathbf{7 2 2}$ 168-176. 